\title{
Polyurethane derived from Ricinus Communis as graft for bone defect treatments
}

\author{
Tatiana Peixoto Telles de Sousa ${ }^{1}$, Maria Silvana Totti da Costa ${ }^{1}$, Renata Guilherme ${ }^{1}$, Wilson Orcini', \\ Leandro de Andrade Holgado ${ }^{1}$, Elcia Maria Varize Silveira' ${ }^{1}$, Orivaldo Tavano², Aroldo Geraldo Magdalena \\ Sérgio Augusto Catanzaro-Guimarães ${ }^{1}$ and Angela Kinoshita ${ }^{1 *}$
}
1Pró-reitoria de Pesquisa e Pós-graduação - PRPPG, Universidade do Sagrado Coração - USC, Bauru, SP, Brasil

${ }^{2}$ Faculdade de Odontologia de Bauru, Universidade de São Paulo - USP, Bauru, SP, Brasil

${ }^{3}$ Faculdade de Ciências, Universidade Estadual Paulista - UNESP, Bauru, SP, Brasil

*angelamitie@gmail.com; angela.kinoshita@usc.br

\begin{abstract}
This work evaluated polyurethane $\left(\right.$ Polyquil ${ }^{\circledR}$ ) as a graft for treatment of bone defects. Bone defects of $1.5 \times 0.5 \mathrm{~cm}$ were made in the calvaria of 16 rabbits. Eight animals had their defects treated with Polyurethane (Treated) and 8 of them had their defects filled with blood clot (Control). In the second experiment, segmental defects of $0.5 \mathrm{~cm}$ were performed at the zygomatic arch of 16 rabbits. Eight animals were treated by guided bone regeneration, using a latex membrane, associated to grafting of polyurethane while the others were not treated (Control). The bone tissue morphometry in the craniotomy experiment resulted in a higher bone volume in the Treated group at 60 days $(p<0.05, t$ student test). Microscopic and radiographic images demonstrate the formation of a bone bridge in the segmental defect, 60 and 120 days after surgery in the Treated group, different from the Control group with incomplete healing.
\end{abstract}

Keywords: biomaterial, bone defect, graft, polyurethane.

\section{Introduction}

During the last decade, several segments of medicine, dentistry, among others, have sought biocompatible materials, harmless to the body, with the aim of replacing tissue. Biocompatible materials, natural or synthetic, can be prepared by different methods. There are many polymers used in dentistry, such as silicone, polyurethane and methyl methacrylate. The vegetable polyurethane, which combines the versatility of polymer formulation with the global concern of new biomaterials production with sustainable resources, has become one of the most studied biomaterials ${ }^{[1,2]}$.

The polyurethane used in the present study - Poliquil ${ }^{\circledR}$ - is a material derived from the Ricinus communis oil, plant shrubs very disseminated in Brazil. It is a plant known in Brazil and throughout the world by the synonyms of palma Christi, carrapateira, castor bean, tartago, "castor oil", "castor bean", probably originating in India ${ }^{[3]}$. This biopolymer has high capacity for interaction with human body cells in addition to not causing rejection. The success of the biopolymer can be explained by its compatibility with the human body ${ }^{[2,4-6]}$.

The chemical composition of this material is formed by a chain of fatty acids whose molecular structure is present in human body fat, which facilitates its recognition. In addition, other advantages are observed which include a molecular formula with favorable aspects of processability; formulation flexibility; no emission of toxic vapors; good cell adhesion ability; non-release of toxic radicals when implanted, besides

low $\operatorname{cost}^{[4]}$. The biodegradation of this polymer by fungal and bacterial attack were demonstrated through Scanning Electron Microscopy (SEM), Thermogravimetry (TGA) and Infrared Spectroscopy (FTIR). The authors demonstrated that the degradation mechanisms are the same used by the microorganisms in fats ${ }^{[7]}$. Trovati et al. ${ }^{[8]}$ used FTIR, TGA and X-ray Diffractometry (DRX) to investigate the rigid, semi rigid, and soft polyurethane obtained through different ratios between pre-polymer and polyol, showing that different ratios cause differences in thermal behavior and crystalline structure of the synthesized polyurethane.

Jena and Gupta ${ }^{[9]}$ reported that traditionally, the plant is used as a laxative, fertilizer and fungicide. It also has beneficial effects such as an anti-oxidant, antihistamic, antinociceptive, antiasthmatic, antiulcer aid, oral immunomodulator, anti-inflammatory, antimicrobial, insecticide and larvicide, a hepatoprotective, fertility aid, central nervous system stimulant, lipolytic, wound healer, and having many other medicinal properties due to phytochemical components such as flavonoids, saponins, glycosides, alkaloids and steroids, among others.

The polymer from Ricinus communis was studied due its biocompatibility and ability to stimulate bone regeneration. Leite and Ramalho ${ }^{[10]}$ developed a study to compare the differences in the reaction of the connective tissue and the jaw bone of rats when exposed to this resin and demineralized bovine bone matrix. The results 
indicate biocompatibility of both materials, considering their integration into the rat jaw, and demonstrating that polyurethane is an alternative in bone reconstruction with the advantage of being an inexhaustible source of biomaterial. In the form of resin, after polymerization, it has pores with a diameter of 120 to $500 \mu \mathrm{m}$, an important characteristic for osteoconductivity, since it allows the growth of the bone tissue in the interior, optimizing the integration between the material and the host bone tissue ${ }^{[11,12]}$. Other studies in animal models demonstrate good results of polymer applied as prosthesis for surgical correction of medial patellar luxation ${ }^{[13]}$ and in the regeneration of segmental bone defects. The granular form showed to be biocompatible and osteointegrated ${ }^{[14]}$.

It was demonstrated that when polyurethane is associated to calcium carbonate or calcium phosphate it can promote bone mass gain by bone matrix mineralization ${ }^{[15,16]}$. It was also observed that upon the incorporation of alkaline phosphatase to the polymer and subsequent incubation in synthetic body fluid, the biological properties of this polymer is improved ${ }^{[17]}$. When compared to the demineralized bone, it has the advantage of being reabsorbed more slowly[ ${ }^{[16]}$

The literature reports the association of polyurethane with other components with the objective of improving their properties as a biomaterial. Nacer et al. ${ }^{[18]}$ describe the biological behavior of the polymer in combination with silica nanoparticles as a bone substitute, in a study on bone defects in rats, showing that the polyurethane is biocompatible and allows osteoconduction. In addition, they reported that the presence of osteoprogenitor cells suggests silica osteoinduction capacity.

Barros et al. ${ }^{[19]}$ evaluated the biocompatibility of three different Ricinus communis Polyurethane chemical compositions; pure, with calcium carbonate and calcium phosphate. They found that the calcium phosphate composite improves biocompatibility and osseointegration speed. In another experimental study on the biocompatibility of the Ricinus communis polymer with addition of calcium carbonate in comparison to titanium, a recognized biocompatible material, it was evidenced that composite was not statistically different from the titanium implant regarding tissue inflammatory reaction ${ }^{[20]}$.

Another biomaterial used in this work is the latex derived from the rubber tree Hevea brasilienses. After the polymerization, a membrane is formed, presenting certain advantages such as: elasticity, flexibility, strength, ability to induce angiogenesis and low $\cos ^{t^{21,22]}}$. Its use as an occlusive membrane for bone regeneration has already been tested in animal models, with satisfactory results ${ }^{[23,24]}$. Other literature data indicate its biocompatibility ${ }^{[25,26]}$, its angiogenic potential ${ }^{[21,27,28]}$ and its ability to act as a drug delivery system ${ }^{[29-31]}$.

Thus, the objective of this work was to study the effect of polyurethane granules $\left(\right.$ Polyquil $^{\circledR}$ ) as graft material in bone regeneration cases. In the first part of the study, surgical defects of $1.5 \times 0.5 \mathrm{~cm}$ were created in the calvaria of 16 rabbits and the polyurethane granules (Poliquil ${ }^{\circledR}$ ) were used as a graft to assist in bone repair. The defect diameter of $1.5 \times 0.5 \mathrm{~cm}$ was chosen because it is similar to the critical size, which it is not repaired without treatment ${ }^{[32]}$. Thus, there would be a difference in responses between periods of 60 and 120 days, which might not occur for defects of smaller size. In the second part of the study, the conditions for the regeneration and restructuring of the zygomatic arch through the guided bone regeneration procedure were observed, using the natural latex membrane as occlusive membrane and polyurethane covering the graft. It was evaluated quantitatively by bone tissue morphometry, the behavior of the polymer material as osteoconductive, compared to the Control group, in which the defects were filled by blood clot.

\section{Materials and Methods}

This study was approved by the Ethics Committee of the Universidade do Sagrado Coração, according to protocol number CEP/USC 26/07 and follows the recommendations set forth by the National Institute of Health $(\mathrm{NIH})^{[33]}$.

Thirty-two adult male New Zealand white rabbits, with an average weight of $3 \mathrm{~kg}$, mean age between four and five months were used. They were maintained under good environmental conditions of food, temperature, hygiene and lighting during the entire experimental period. Sixteen animals were used in the calvaria defect experiments, using polyurethane as an intraosseous graft and 16 in the zygomatic arch segmental defect repair study.

The polyurethane granules were purchased from Poliquil ${ }^{\circledR}$ (Araraquara, Brazil); granulation $450 \mu \mathrm{m}$ and commercialized in $5 \mathrm{~g}$ doses. This granulation allows the metabolization and formation of new bone tissue through the osteogenic cells. Figure 1 shows the infrared spectrum (FTIR) of the material using a Vertex 70 spectrometer (Bruker instruments). The description of bands are described in Table 1 and in agreement with Trovati et al. ${ }^{[8]}$.

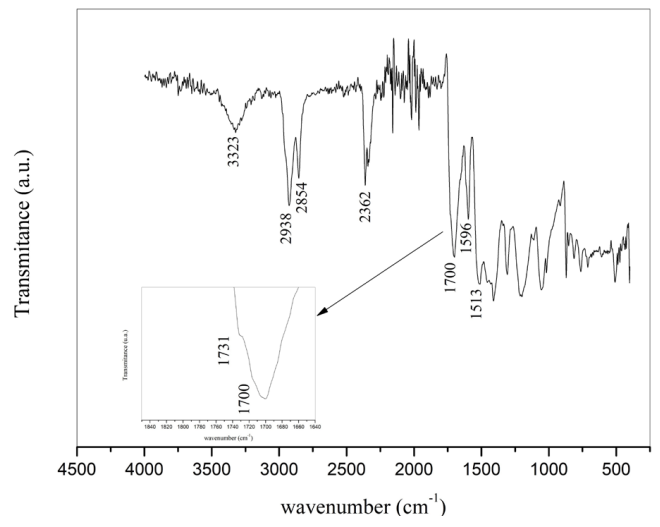

Figure 1. FTIR spectrum of polyurethane granules. The main bands are indicated and their descriptions are in Table 1.

Table 1. FTIR bands assignment of polyurethane spectrum showed in Figure 1.

\begin{tabular}{cc}
\hline Bands & Description \\
\hline 3323 & O-H stretching \\
2925 & C-H symmetrical stretching \\
2854 & C-H asymmetrical stretching \\
1731 & $\mathrm{C}=$ O stretching \\
1700 & $\mathrm{C}=$ O stretching \\
$1596 ; 1513$ & $\mathrm{~N}-\mathrm{H}$ angular deformation \\
\hline
\end{tabular}


The latex membrane was prepared as described by Guidelli et al. ${ }^{[30]}$. The colloidal solution of latex was provided by BDF Com Prod Agrícolas LTDA, Brazil and consisted of a mix of an extract of several $H$. brasiliensis clones. After extraction, the $\mathrm{pH}$ was adjusted to 10 with ammonium hydroxide $\left(\mathrm{NH}_{4} \mathrm{OH}\right)$ in order to avoid coagulation and the solution centrifuged at $8,000 \mathrm{~g}$, to reduce the amount of allergenic proteins ${ }^{[34]}$. The solution was then polymerized at ambient temperature in $15 \mathrm{~cm}$-diameter Petri plates to produce a $2 \mathrm{~mm}$-thick membrane. After this procedure, the membranes were sterilized by gamma radiation $(25 \mathrm{kGy})$ for use in surgical procedures. During the procedure, the membranes were cut to a size which was slightly larger than the surgical defect $(2 \mathrm{~cm} \times 1 \mathrm{~cm})$, to facilitate their fixation. Guidelli et al. ${ }^{[30]}$ described the FTIR spectrum of a latex membrane that is the same as that used in this present work.

\subsection{Polyurethane as intraosseous graft}

The 16 animals were submitted to a surgical procedure for craniotomy under deep sedation (xylazine hydrochloride $10 \mathrm{mg} / \mathrm{kg}$ (Bayer, Brazil), followed by Ketamine hydrochloride $90 \mathrm{mg} / \mathrm{kg}$ (Vetbrands, Brazil) administration, also intramuscular, complemented with mepivacaine hydrochloride $2 \%$ with epinephrine 1:100,000 as local anesthetic, for purposes of ischemia in the preparation of surgical defects. The frontal and parietal bone were submitted to trichotomy, followed by antisepsis with PVPI (Polyvinylpyrrolidone iodine solution) topical application. A mucoperiostal linear incision, in the median line, in the frontal bone, with No. 15 scalpel blade, followed by muscle divulsion and periostal were performed. The separation of soft tissues was carried out in layers, exposing the parietal bones.

A trephine bur, $0.5 \mathrm{~cm}$ in diameter, driven by a low speed rotation motor was used to make three perforations, under abundant irrigation with saline solution (sodium chloride $0.9 \%$ ), removing all the cortical bone and cancellous bone, exposing the dura mater, configuring a bone defect of elliptical shape, $1.5 \times 0.5 \mathrm{~cm}$ and depth equal to the thickness of the cortical bone. Whole bone within the defect was removed with caution to expose the dura mater, because there was a risk of dura mater damage. All bone was removed without leaving bone spicules, to observed and compare, with fidelity, the bone growth from the blood clot and with the implanted materials. Technically, there is no way to leave a thin layer of bone on the dura mater, as there is no way to control whether all the animals are left with exactly the same thickness of this bone layer, resulting in errors in the results. Complete removal ensures uniformity of all defects.

The animals belonging to the Control group $(n=8)$ had the defects filled only by a blood clot (Figure 2A), followed by suturing in layers, first of the periosteum, followed by the skin suture. In the Treated group $(n=8)$, the defects were filled with Polyurethane granules mixed in a blood clot (Figure 2B). The tissue was also immediately repositioned and sutured in layers, first of the periosteum followed by the skin suture. The animals received single dose of sodium dipyrone analgesic ( $25 \mathrm{mg} / \mathrm{kg}$ Fort Dodge, Brazil).

Four animals of the Treated group and 4 of the Control group were submitted to euthanasia with an overdose of Sodium pentobarbitone (200 mg/kg IP), 60 and 120 days postoperatively.

The specimens containing the bone defect were removed and preserved in $10 \%$ formalin and subsequently submitted to radiological and microscopic analysis.

\subsection{Repair of segmental defect in the zygomatic arch}

Induction of deep sedation was done the same way as in the previous experiment. After shaving the area to be operated, a skin incision, $4 \mathrm{~cm}$ in length was performed with a Number 15 scalpel blade following the zygomatic arch bones. After the skin incision and divulsion of the musculature of the region, a new incision was made in the periosteum for exposure of whole bone tissue in the region of the zygomatic complex. The demarcation of the size of the defect was made using a trephine drill with diameter of $0.5 \mathrm{~cm}$, driven by a low speed rotation motor with abundant irrigation using saline solution (sodium chloride $0.9 \%$ ), in the central area of the zygomatic arch. Figure 3A illustrates the region where the defect was made.

After the demarcation, the delimited bone segment was removed using Rongeur forceps. The edges of the defect

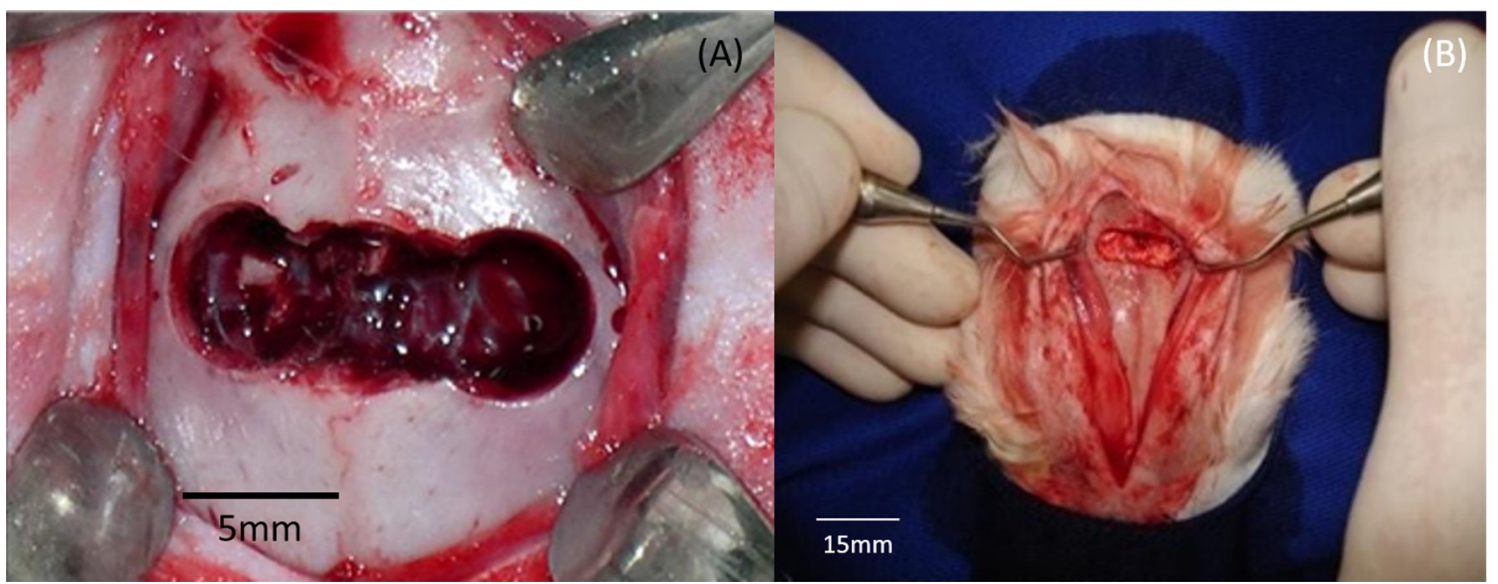

Figure 2. Bone defect created in the skull cap with elliptical shape and dimensions of $1.5 \mathrm{~cm} \times 0.5 \mathrm{~cm}$. (A) Defect filled by blood clot; (B) Defect filled with granulated polyurethane and blood clot. 


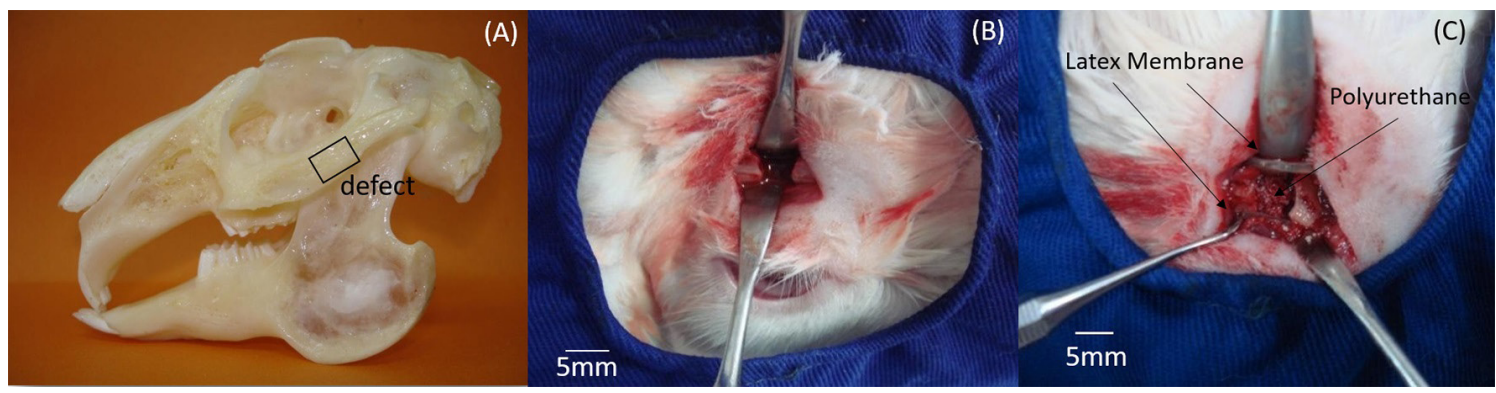

Figure 3. (A) Photograph of the bony structure of the rabbit skull showing the zygomatic arch and the region where the defect was created; (B) Segmental bone defect created in Control group, without treatment; (C) Segmental bone defect of the Treated group, enveloped by Latex membrane and filled with granulated polyurethane.

were conveniently regularized with an osteotome, taking care to remove all cortical bone without leaving bone spicules.

In the Control group (Figure 3B), after the creation of segmental bone defect, the tissue was repositioned and simple sutures were placed in the periosteum and musculature and continuous in the skin with 3-0 silk suture (Ethicon).

In the Treated group, the latex membrane was molded into cylindrical form to join the stumps of the defects. The inside of the membrane was filled with polyurethane granules mixed with blood clot (Figure 3C). Ethyl-cyanoacrylate adhesive was used for fixing the membrane on the stumps. The tissues were repositioned and sutured as described.

Immediately after the surgical procedure the animals received single dose sodium dipyrone analgesics $(25 \mathrm{mg} / \mathrm{kg}$ Fort Dodge, Brazil) intramuscularly.

Four animals of the Treated group and 4 of the Control group were submitted to euthanasia with an overdose of Sodium pentobarbitone (200 mg/kg IP), 60 and 120 days postoperatively.

The specimens containing the bone defect were removed and preserved in 10\% formalin and subsequently submitted to radiological and microscopic analysis.

\subsection{Radiographic analysis}

Digital radiographic images were taken using the Digora System in both experiments. Initially, the excessive humidity of the samples of the skull cap and the zygomatic arch was removed with a tissue.

The positioning of the pieces was standardized: horizontally and parallel along the axis of the specific image plate of the Digora system, placed on a flat surface, covered by a Styrofoam piece.

The dental X-ray equipment was regulated to $70 \mathrm{kV}$ and $8 \mathrm{~mA}$, and total filtration equivalent to $2 \mathrm{~mm}$ of aluminum was used. The cylinder was positioned so that the beam was incident perpendicularly on the film plane with $40 \mathrm{~cm}$ focal distance and $2 \mathrm{mAs}$ exposure, previously selected.

The sensitized image plate was positioned in the optical reader of the Digora System for later capture of the latent image contained in the active portion of the plate, through laser scanning. The software "Digora for Windows" was used for image analyses.

\subsection{Scanning electron microscopy}

A sample from the 60-day group was analyzed by scanning electron microscopy. Briefly, the sample was dehydrated with solutions of increasing concentrations of Ethanol (35\%, 50\%, 75\%, 95\% and absolute), dried in an oven at $37^{\circ} \mathrm{C}$ and subsequently covered with a layer of gold (Sputter Coater SCD 050). The sample image was performed using microscope Leica-Steroscan 440.

\subsection{Microscopic analysis}

After fixation, the pieces were rinsed in tap water and decalcified following the Morse method (50\% formic acid and $20 \%$ sodium citrate aqueous solution). Subsequently, the microscopic preparation of usual procedures were performed.

Three sections with $6 \mu \mathrm{m}$ thick were performed in the region of greater amplitude of the bone defect in the skull. Two of these sections were stained with Masson's trichrome for histomorphometry, and one, stained with hematoxylin-eosin (HE). For zygomatic arch experiment, two slices with $6 \mu \mathrm{m}$ thick, one for each stain.

\subsection{Morphometric analysis}

The morphometric analysis was performed on the samples containing bone defect obtained by craniotomy using the Image-Pro Plus Software (Media Cybernetics), installed on a microcomputer coupled to a Nikon Eclipse $80 \mathrm{i}$ photomicroscope. Quantification of immature bone tissue, mature fibrovascular stroma in the region of the defect, was performed.

\section{Results and Discussions}

\subsection{Polyurethane as intraosseous graft}

After the observation periods of 60 and 120 days, the presence of newly formed bone was macroscopically observed in the region of the defect in the pieces of the Treated group. In the Control group, the region of the defect presented scar tissue covering the defect, this tissue was thicker but not rigid like the bone tissue found in the Treated group.

Radiographic analysis at 60 days in the Control group samples shows that most of the defect region is filled by a radiolucent area, with small radiopaque areas near the edges of the defect (Figure 4A, red arrows). In the Treated group, 


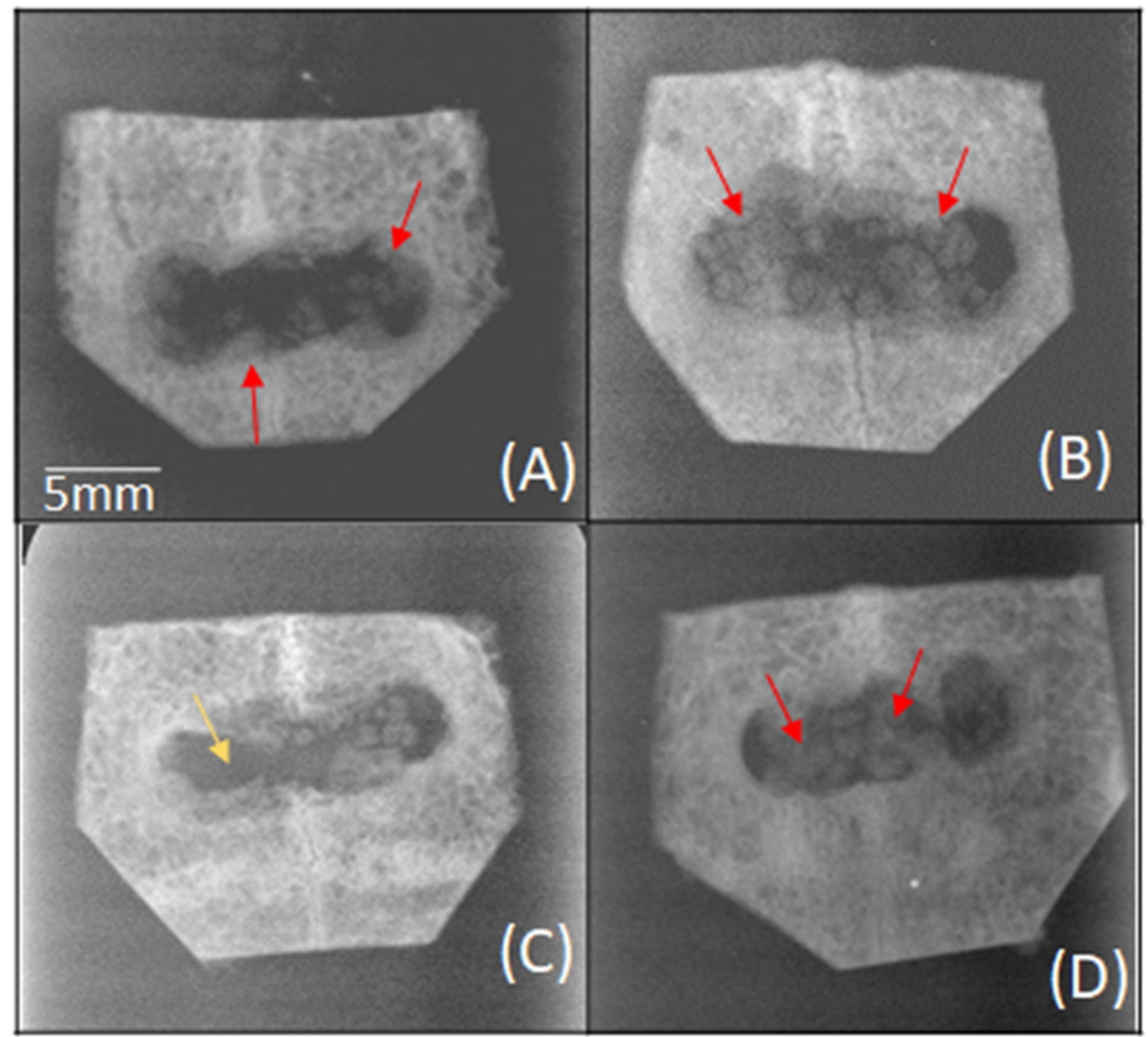

Figure 4. Radiograph at 60 days (A and B) and 120 days (C and D) of Control (A and C) and Treated (B and D) groups. (A) Control Group 60 days - there are small radiopaque areas near the edge of the defect (red arrows) and radiolucency in most of the region of the defect; (B) Treated group 60 days - radiopaque areas accompanying the entire extent of the defect (red arrow); (C) Control Group 120 days - areas of radiopacity located on the margin of the defect and radiolucency in most of the central region (yellow arrow); (D) Treated group 120 days - areas of radiopacity at the margins and central region of the defect (red arrows).

most of the region of the defect is filled by a radiolucent area, with radiopaque areas accompanying the edges of the defect and dispersed as isolated areas throughout the defect (Figure 4B, red arrows). At 120 days, digital radiography of the Control group shows a radiopaque area located specifically on the defect margin as in this example, in the right margin region. There are regions of radiolucency at the left end and at the center of the defect (Figure 4C, yellow arrow). In the Treated group, at 120 days, regions of radiopacity are noted in much of the central region of the defect (Figure 4D, red arrows).

Figure 5A shows the photomicrography of the Control group bone defect at 60 days. The main features presented are: intramembranous ossification with absence of cartilage, presence of areas of immature bone tissue (black arrow) in the internal and external bone plates, and intertrabecular bone in formation. Figure 5B shows the photomicrograph at 60 days of the Treated group, which received the Polyurethane that was mixed with the clot. There is a repair process by intramembranous ossification with absence of cartilage. Bone regeneration observed around the polyurethane particles is observed throughout the bone defect (black rectangle). Figure 5C shows in higher magnification bone marrow tissue $(*)$, mature bone tissue $(+)$ and immature bone tissue (\#). Figure 5D shows the photomicrograph of the defect of the Control group at 120 days. The main features presented are: bone neofornation in the interparietal suture region (black rectangle) and poor definition of the external and internal bone plates, besides the presence of immature reticular bone tissue interspersed with trabeculae of lamellar bone. Osteogenic connective tissue was still visible in some areas. In the Treated group at 120 days (Figure 5E) the main features seen are: newly formed bone, particles of granulated polyurethane implanted in the surgical bone bed (green arrow), formation of mineralized bone matrix on the surfaces of the osseointegrated particles. In some areas, the remodeling of the bone/particle ensemble shows a mosaic composed of immature bone tissue, lamellar mature bone and osteogenic connective tissue in small proportions (red arrow). In a higher magnification image (Figure 5F), there was no foreign body type inflammatory reaction and areas where remodeling of the bone/particle occurred (green arrow). The material proved to be biocompatible and osteointegratable.

Figure 6 shows SEM images of samples retrieved at 60 days post surgery. The images show the integration of polyurethane particles with bone tissue confirming the histological findings. Some particles are indicated by red arrows. 
Figure 7 shows the histomorphometry of the newly formed bone and fibrovascular stroma (FS) for periods of 60 (Figure 7A) and 120 days (Figure 7B). At 60 days there is a greater amount of newly formed bone (NFB) in the Treated group compared to the Control $(p<0.05, t$ test). Also, the fibrovascular stroma volume is higher in the Control group ( $p<0.05$, t test). However, after 120 days, the amount of bone tissue is the same in both groups (Figure 7B), despite the amount of fibrovascular stroma being lower in the Treated group. As such, we can note that the presence of the Polyurethane sped up the bone repair process.

In a similar study, Boeck-Neto et al. ${ }^{[15]}$ found satisfactory results in facial bone repair. The authors compared the use of calcium phosphate and Ricinus communis, both associated with autogenous bone, to increase the maxillary sinus floor, resulting in a bone mass gain in both groups, but emphasized

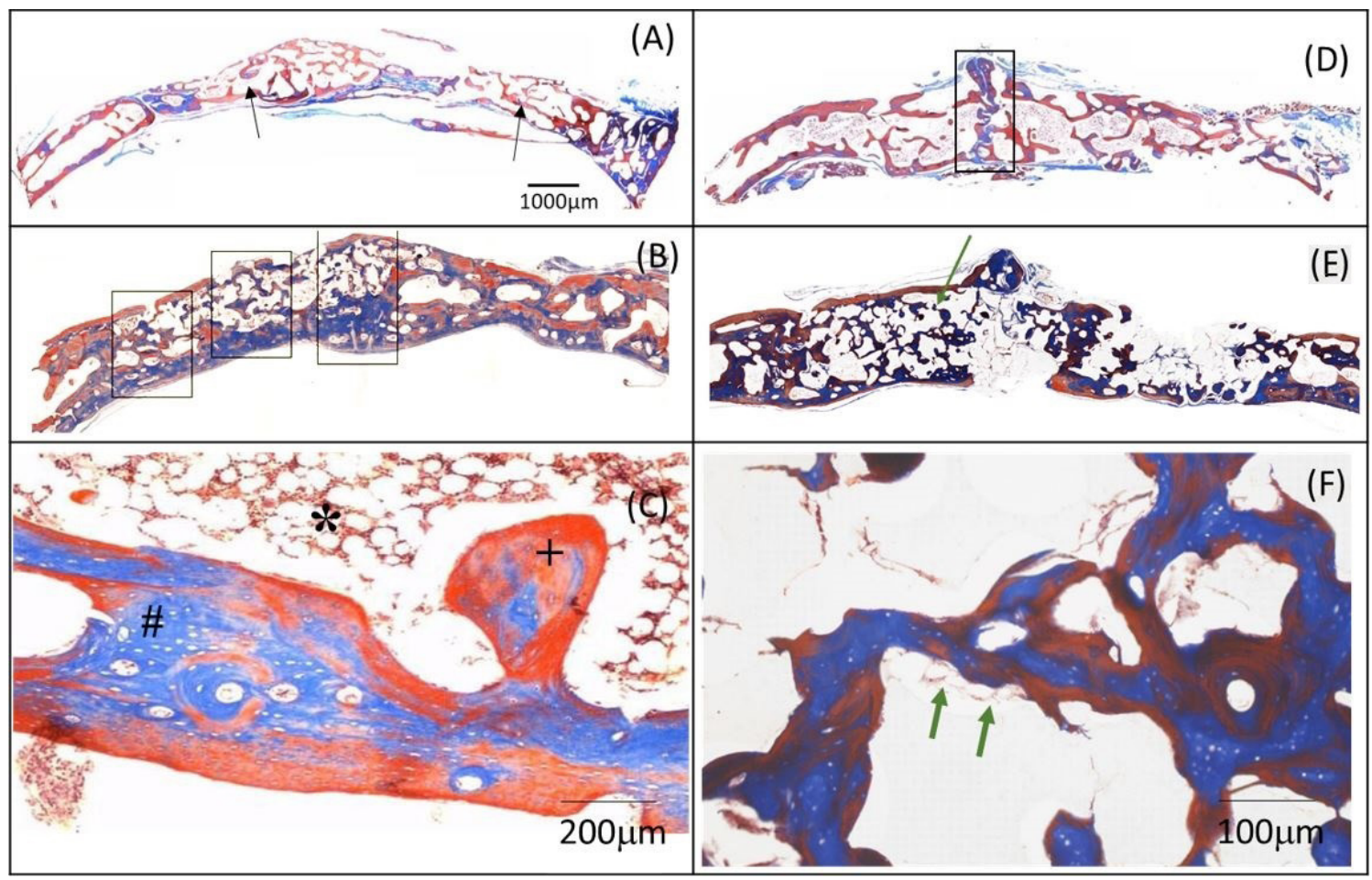

Figure 5. Histological section of the bone defect. Masson's trichrome. (A) Control Group - 60 days (2X). Areas of immature bone tissue are verified (black arrow); (B) Treated group - 60 days (2X). In the region marked by a rectangle, some particles covered by a thin layer of osteogenic connective tissue and immature bone (black arrow) are noticed. At higher magnification (10X) (C) bone marrow tissue $(*)$, mature bone tissue (+) and immature bone tissue (\#) are observed; (D) Control Group -120 days (2X). In the region delimited by a rectangle there is a large volume of newly formed bone tissue in the region of the interparietal suture and little definition of external and internal bone plates; (E) Treated group - 120 days (2X) showing advanced bone repair process. At higher magnification (F) (20X) some areas (green arrows) present remodeling of the bone / particle.
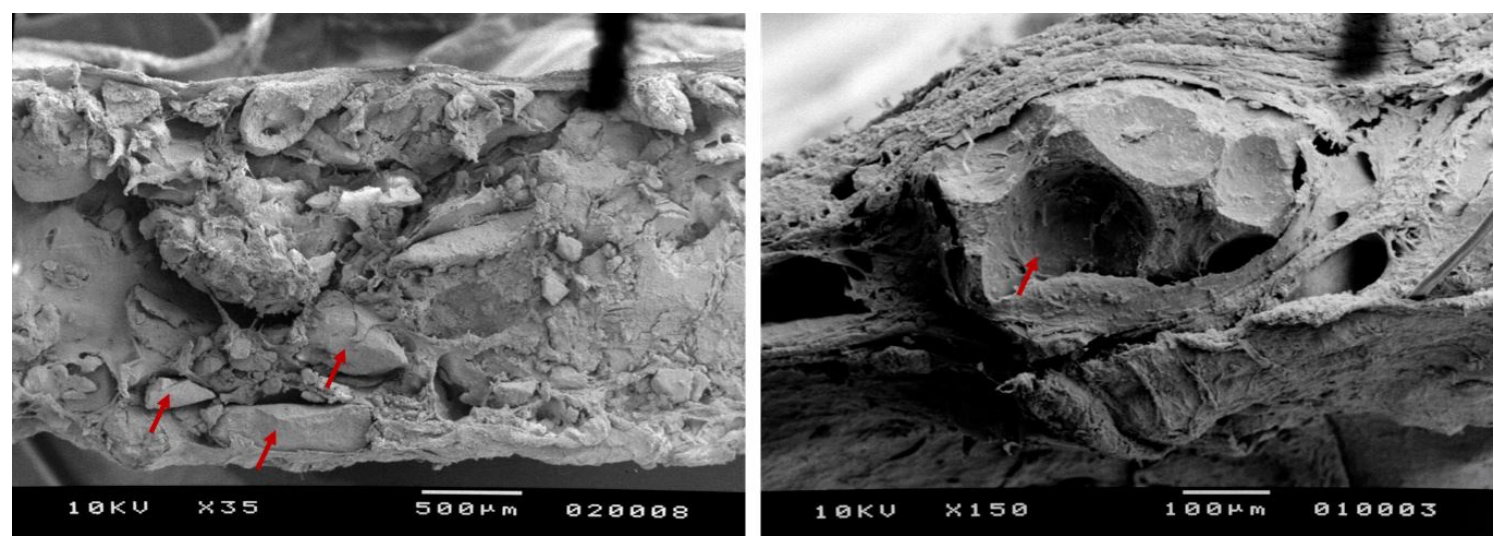

Figure 6. SEM images of section of the bone defect 60 days post surgery showing the integration between polyurethane particles (red arrow) and bone tissue. 
that the graft materials, that were biocompatible, were not completely reabsorbed after 10 months, but integrated into the bone.

\subsection{Repair of segmental defect in the zygomatic arch}

Macroscopically, the pieces obtained from the Treated group with polyurethane and latex membrane were analyzed and showed growth of mineralized bone joining the stumps of the zygomatic arch. In the Control group, the pieces obtained in periods of 60 and 120 days showed scar tissue in the region of the defect.

Figure 8 presents X-ray images of Control and Treated groups in both observation periods, 60 and 120 days.

In the images of the Control group at 60 days (Figure 8A), there is a radiopaque area in the stumps of the zygomatic arch (white arrow) and a radiotransparent area in the bone

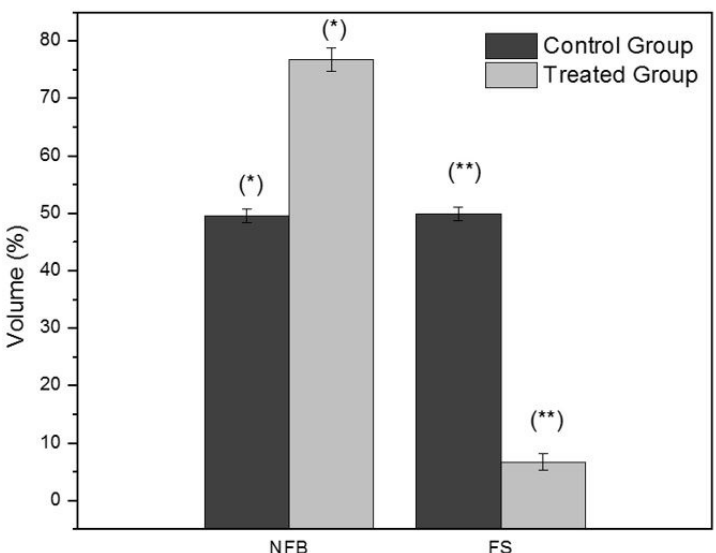

(A)

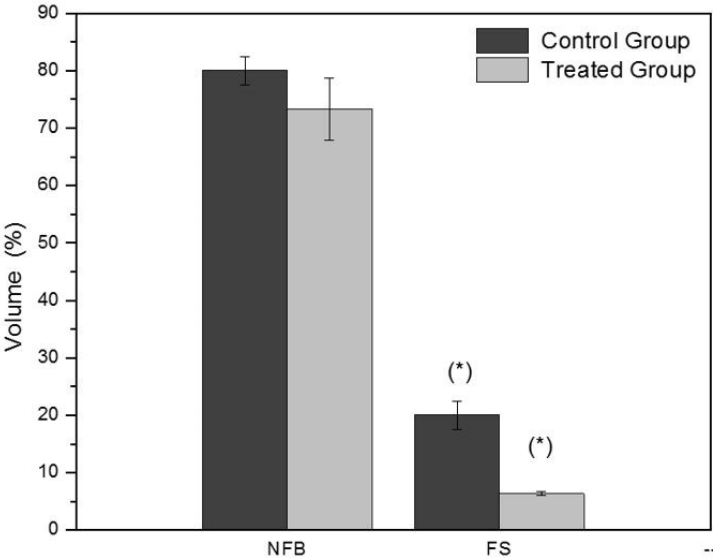

(B)

Figure 7. Mean and standard deviation of volume fraction values of newly formed bone tissue (NFB) and fibrovascular stroma (FS) in bone defects obtained by craniotomy and treated with Polyurethane as a function of observation periods compared to Control group (A) 60 days and (B) 120 days. Statistically significant differences are indicated by $(*)$ and $(* *)(p<0.05 t$-test).

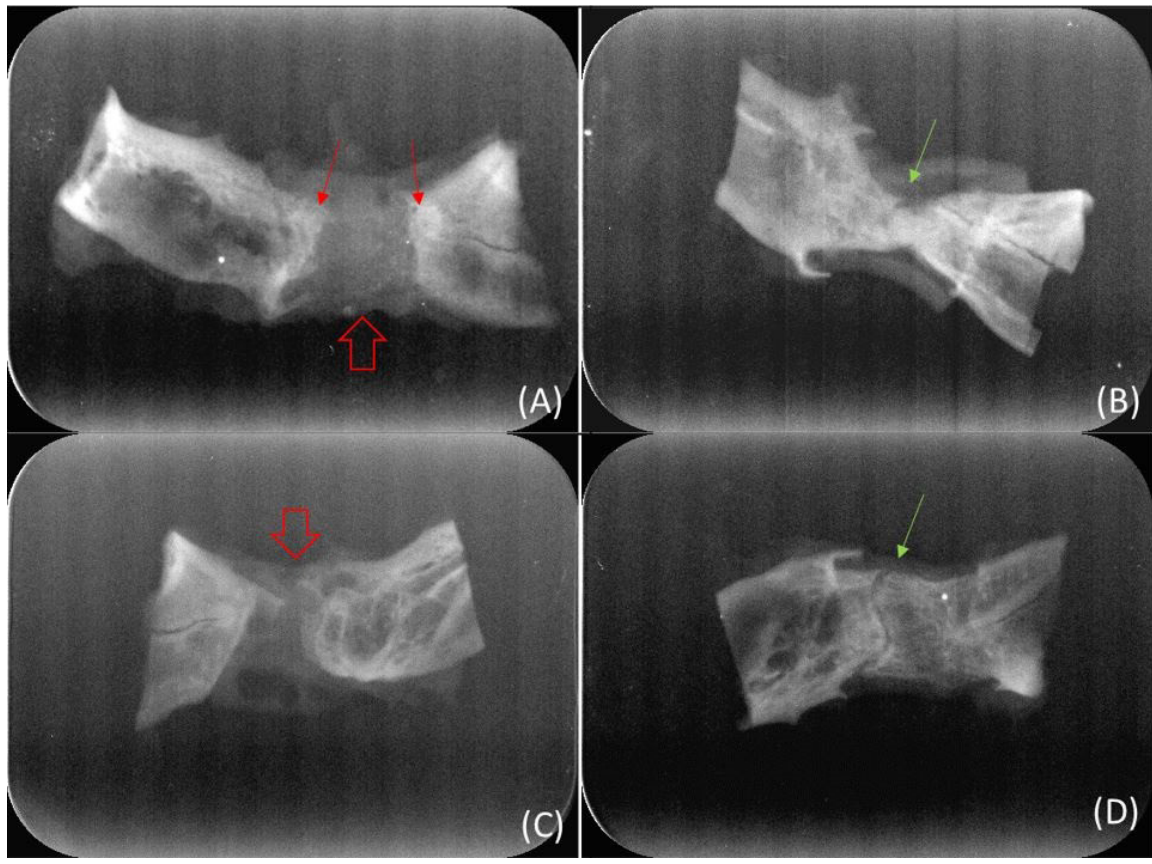

Figure 8. Digital radiography of the rabbit zygomatic arch of the Control and Treated groups at 60 days (A and B) and 120 days (C and D). (A) In the image of the Control group at 60 days the zygomatic arch stump region (red arrows) can be seen and the entire bone defect region with radiolucency (wide red arrow); (B) In the Treated group - 60 days there is an area of radiopacity connecting the stumps of the bony defect forming a bridge between the stumps (green arrow); (C) In the image of the Control group - 120 days radiolucency (wide arrow) in the region of the defect can also be seen; (D) In the Treated group at 120 days, a radiopaque area can be seen connecting the bony defect stumps, forming a bony bridge between them. 
defect region (red arrow). In the Treated group (Figure 8B) there is a narrow region of radiopacity joining the stumps, forming a bridge between them (green arrow).

In the images of the Control group - 120 days (Figure 8C) there is a radiotransparency in the center of the bone defect (red arrow). In this example, there is a small region of greater radiopacity in an area in the top margin to the right of the defect. The radiographic image of the Treated group at 120 days (Figure 8D) there is a homogeneous and greater radiopacity area joining the stumps, going toward the center of the defect, forming a thicker bone bridge compared to the 60 -day period. In this example there is a thin radiotransparent line in the center of the defect in an $s$ shape (green arrow).

Figure 9A shows a photomicrograph of the region of the bone defect created in the zygomatic arch of the Control group 60 days post-surgery. The main structures presented are: incomplete bone repair process, with the presence of immature bone tissue and fibrous connective tissue (black arrow). In contrast, in the Treated group with polyurethane and Latex membrane (Figure 9B) there is a repair process via intramembranous ossification, with absence of cartilage. The complete covering of the bone defect by guided bone regeneration through the polyurethane particles associated to latex membrane can also seen. In addition, the bone trabeculae under growth (green arrow) are observed along the edges of the bone surgical cavity and organized bony structure in the margin of the bone surgery (black arrow). At higher magnification, osteogenic connective tissue involving particles of material implanted in metabolization process can be seen. A cement line on the surface of the particles is also present. (Figure 9E, black arrow). Figure 9C presents a photomicrograph of the bone defect in the zygomatic arch for the 120-day period of the Control group. The main characteristics presented are: still incomplete bone repair process, with the presence of immature bone tissue and fibrous connective tissue (black arrow). In the Treated group at 120 days (Figure 9D) the main characteristics present are: a repair process via intramembranous ossification, with absence of cartilage, the covering of the bone defect by bone regeneration guided through the particles from the implanted material. At higher magnification (Figures 9F and G) the presence of newly formed bone tissue involving the polyurethane particles is notice, also areas under an active remodeling process (Figure 9F marked with *). Bone trabeculae that separated the particles among themselves, but integrated bone/particles

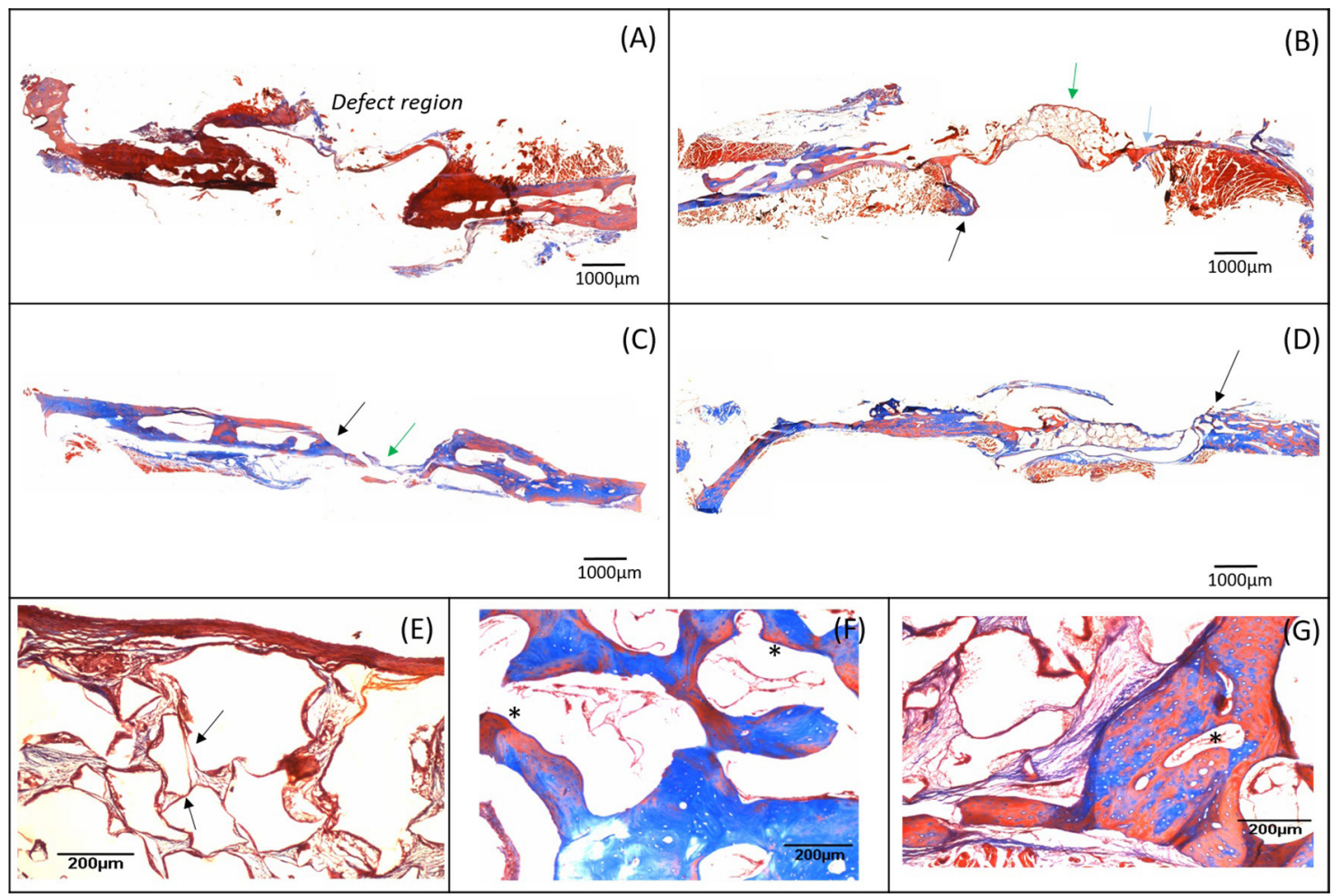

Figure 9. Photomicrographs of the histological sections of the bone defect in the zygomatic arch region (Masson's trichrome stain) (A) Control group - 60 days (2X) there is immature bone tissue presence and incomplete bone repair; (B) 60-days treated group (2X) the particles present in the region of the defect (green arrow) and growing bone trabeculae (black arrow) and organized bone structure on the margin of the surgical bone defect (blue arrow) are observed. At higher magnification (10X) (E) it is possible to observe the deposition of a cement line on the surface of the particles (black arrows, 10X); (C) The Control group at 120 days (2X) immature bone tissue (black arrow) and incomplete bone repair process (green arrow) are observed; (D) Treated group - 120 days (2X)presents the formation of the bone bridge attached to the stumps, and presence of newly formed bone on the border of the defect (black arrow). At higher magnification (F) $(20 \mathrm{X})$ particles implanted in areas under active remodeling process $\left(^{*}\right)$ can be seen. $\operatorname{In}(\mathrm{G}),(20 \mathrm{X})$ polyurethane particle with metabolic signs $(*)$ becomes rarefied and leaves empty spaces between the growing bone trabeculae. 
with the bone cavity walls is also noticed (Figure 9F, G). Polyurethane particles with signs of metabolization becoming rarefied (Figure 9G marked with *) and leaving empty spaces between growing bone trabeculae.

These results are in agreement with a previous study conducted by Pereira ${ }^{[14]}$, who compared the polyurethanes containing castor oil in granular form with a spongy autogenous bone graft applied to a segmental bone defect in rabbit and concluded that the regeneration process was more evident and accelerated in the bone defects treated with spongy bone autotransplantation, but the polyurethane also induced bone regeneration. The authors described that the polyurethane acts as a filling material, minimizing the local production of fibrous tissue, similar to that found in this present work. In addition, in our work we also noted the absence of inflammatory reaction type foreign body and that the material is biocompatible and osteointegrable.

Histological results in both experiments (Figures 5 and 9) demonstrated more pronounced bone formation in defects with granulated polyurethane graft as compared to their respective controls which can also be seen in $\mathrm{x}$-ray images. In addition, the osseointegration of the polyurethane particles in contact with immature bone tissue and osteogenic connective tissue can be observed both in optical and scanning electron microscopy images.

\section{Conclusions}

Polyurethane is a biocompatible, osteoconductive and osteointegrable material, which promotes new bone formation in both bone defects studied, it thus being an interesting option in bone defect treatments. The association with a latex membrane produced regeneration of segmental bone defects.

\section{Acknowledgements}

The authors are grateful to Maira Couto for the technical assistance and FAPESP (São Paulo Research Foundation) for partial financial support.

\section{References}

1. Derceli, J. R., Fais, L. M., \& Pinelli, L. A. (2014). A castor oil-containing dental luting agent: effects of cyclic loading and storage time on flexural strenght. Journal of Applied Oral Science, 22(6), 496-501. http://dx.doi.org/10.1590/1678775720140069. PMid:25591018.

2. Monteiro, A. S., Macedo, L. G., Macedo, N.-L., \& Balducci, I. (2010). Polyurethane and PTFE membranes for guided bone regeneration: histopathological and ultrastructural evaluation. Medicina Oral, Patologia Oral y Cirugia Bucal, 15(2), e401-e406. http://dx.doi.org/10.4317/medoral.15.e401. PMid:19767699.

3. Lim, T. K. (2012). Ricinus communis. In T. K. Lim (Ed.), Edible medicinal and non-medicinal plants. Netherlands: Springer. http://dx.doi.org/10.1007/978-94-007-1764-0_64.

4. Eglin, D., Grad, S., Gogolewski, S., \& Alini, M. (2010). Farsenol modified biodegradable polyurethanes for cartilage tissue engineering. Journal of Biomedical Materials Research. Part A, 92(1), 393-408. http://dx.doi.org/10.1002/jbm.a.32385. PMid:19191318.
5. Laureano, J. R., Fo., Andrade, E. S. S., Albergaria-Barbosa, J. R., Camargo, I. B., \& Garcia, R. R. (2009). Effects of demineralized bone matrix and a 'Ricinus communis' polymer on bone regeneration: a histological study in rabbit calvaria. Journal of Oral Science, 51(3), 451-456. http://dx.doi. org/10.2334/josnusd.51.451. PMid:19776514.

6. Barros, V. M. R., Rosa, A. L., Beloti, M. M., \& Chierice, G. (2003). In vivo biocompatibility of three different chemical compositions of Ricinus communis polyurethane. Journal of Biomedical Materials Research. Part A, 67(1), 235-239. http:// dx.doi.org/10.1002/jbm.a.10105. PMid:14517881.

7. Cangemi, J. M., Claro, S., No., Chierice, G. O., \& Santos, A. M. (2006). Study of the biodegradation of a polymer derived from castor oil by scanning electron microscopy, thermogravimetry and infrared spectroscopy. Polimeros: Ciência e Tecnologia, 16(2), 129-135. http://dx.doi.org/10.1590/ S0104-14282006000200013.

8. Trovati, G., Sanches, E. A., Claro, S., No., Mascarenhas, Y. P., $\&$ Chierice, G. O. (2009). Characterization of polyurethane resins by FTIR, TGA, and XRD. Journal of Applied Polymer Science, 115(1), 263-268. http://dx.doi.org/10.1002/app.31096.

9. Jena, J., \& Gupta, A. K. (2012). Ricinus communis linn: a phytopharmacological review. International Journal of Pharmacy and Pharmaceutical Sciences, 4(4), 25-29. Retrieved in 2017, May 2, from http://www.ijppsjournal.com/Vol4Issue4/4695. pdf

10. Leite, F. R. M., \& Ramalho, L. T. O. (2008). Bone regeneration after demineralized bone matrix and castor oil (Ricinus communis). Journal of Applied Oral Science, 16(2), 122-126. http://dx.doi. org/10.1590/S1678-77572008000200008. PMid:19089203.

11. Belmonte, G. C., Catanzaro-Guimarães, S. A., Sousa, T. P. T., Carvalho, R. S., Kinoshita, A., \& Chierici, G. O. (2013). Qualitative histologic evaluation of the tissue reaction to the polyurethane resin (ricinus communis-based biopolymer) implantation assessed by light and scanning electron microscopy. Polimeros: Ciência e Tecnologia, 23(4), 462-467. http://dx.doi. org/10.4322/polimeros.2013.063.

12. Saran, W. R., Chierice, G. O., Silva, R. A. B., Queiroz, A. M., Paula-Silva, F. W. G., \& Silva, L. A. B. (2014). Castor oil polymer induces bone formation with high matrix metalloproteinase-2 expression. Journal of Biomedical Materials Research. Part A, 102(2), 324-331. http://dx.doi.org/10.1002/jbm.a.34696. PMid:23670892.

13. Frazilio, F. O., Rossi, R., Negrini, J. M., No., Facco, G. G., Ovando, T. M., \& Fialho, M. P. F. (2006). Use of castor oil polyurethane in an alternative technique for medial patella surgical correction in dogs. Acta Cirurgica Brasileira, 21(Suppl 4), 74-79. http://dx.doi.org/10.1590/S0102-86502006001000016. PMid:17293971

14. Pereira-Júnior, O. C. M., Rahal, S. C., Iamaguti, P., Felisbino, S. L., Pavan, P. T., \& Vulcano, L. C. (2007). Comparison between polyurethanes containing castor oil (soft segment) and cancellous bone autograft in the treatment of segmental bone defect induced in rabbits. Journal of Biomaterials Applications, 21(3), 283-297. http://dx.doi.org/10.1177/0885328206063526. PMid: 16543284.

15. Boeck-Neto, R., Gabrielli, M., Shibli, J., Marcantonio, E., Lia, R. C. C., \& Marcantonio, E., Jr. (2005). Histomorphometric evaluation of human sinus floor augmentation healing responses to placement of calcium phosphate or ricinus communis polymer associated with autogenous bone. Clinical Implant Dentistry and Related Research, 7(4), 181-188. http://dx.doi. org/10.1111/j.1708-8208.2005.tb00063.x. PMid:16336909.

16. Rana, M., Dhamija, H., Prashar, B., \& Sharma, S. (2012). Ricinus communis L.: a review. International Journal of Chemtech Research, 4(4), 706-711. Retrieved in 2017, May 2, from http:// 
sphinxsai.com/2012/oct-dec/Pharmpdf/PT=48(1706-1711) OD12.pdf

17. Beloti, M. M., Oliveira, P. T., Tagliani, M. M., \& Rosa, A. L. (2008). Bone cell responses to the composite of Ricinus communis polyurethane and alkaline phosphatase. Journal of Biomedical Materials Research. Part A, 84(2), 435-441. http:// dx.doi.org/10.1002/jbm.a.31344. PMid:17618485.

18. Nacer, R. S., Poppi, R. R., Carvalho, P. D. T. C., Silva, B. A. K., Odashiro, A. N., Silva, I. S., Delben, J. R. J., \& Delben, A. A. S. T. (2012). Castor oil polyurethane containing silica nanoparticles as filling material of bone defect in rats. Acta Cirurgica Brasileira, 27(1), 56-62. http://dx.doi.org/10.1590/ S0102-86502012000100010. PMid:22159440.

19. Barros, V. M., Rosa, A. L., Beloti, M. M., \& Chierice, G. (2003). In vivo biocompatibility of three different chemical compositions of Ricinus communis polyurethane. Journal of Biomedical Materials Research. Part A, 67(1), 235-239. http:// dx.doi.org/10.1002/jbm.a.10105. PMid:14517881.

20. Graça, Y. L. S. S., Opolski, A. C., Barboza, B. E. G., Erbano, B. O., Mazzaro, C. C., Klostermann, F. C., Sucharski, E. E., \& Kubrusly, L. F. (2014). Biocompatibility of Ricinus communis polymer with addition of calcium carbonate compared to titanium: experimental study in guinea pigs. Revista Brasileira de Cirurgia Cardiovascular, 29(2), 272-278. http://dx.doi. org/10.5935/1678-9741.20140030. PMid:25140479.

21. Mendonça, R. J., Maurício, V. B., Teixeira, Lde. B., Lachat, J. J., \& Coutinho-Netto, J. (2010). Increased vascular permeability, angiogenesis and wound healing induced by the serum of natural latex of the rubber tree Hevea brasiliensis. Phytotherapy Research, 24(5), 764-768. http://dx.doi.org/10.1002/ptr.3043. PMid:19943314.

22. Herculano, R. D., Silva, C. P., Ereno, C., Guimaraes, S. A. C., Kinoshita, A., \& Graeff, C. F. O. (2009). Natural rubber latex used as drug delivery system in guided bone regeneration (GBR). Materials Research, 12(2), 253-256. http://dx.doi. org/10.1590/S1516-14392009000200023.

23. Ereno, C., Guimarães, S. A. C., Pasetto, S., Herculano, R. D., Silva, C. P., Graeff, C. F. O., Tavano, O., Baffa, O., \& Kinoshita, A. (2010). Latex use as an occlusive membrane for guided bone regeneration. Journal of Biomedical Materials Research. Part A, 95(3), 932-939. http://dx.doi.org/10.1002/ jbm.a.32919. PMid:20845492.

24. Moura, J. M. L., Ferreira, J. F., Marques, L., Holgado, L., Graeff, C. F. O., \& Kinoshita, A. (2014). Comparison of the performance of natural latex membranes prepared with different procedures and PTFE membrane in guided bone regeneration (GBR) in rabbits. Journal of Materials Science: Materials in Medicine, 25(9), 2111-2120. http://dx.doi.org/10.1007/s10856014-5241-1. PMid:24849612.

25. Floriano, J., Mota, L., Furtado, E., Rossetto, V., \& Graeff, C. O. (2013). Biocompatibility studies of natural rubber latex from different tree clones and collection methods. Journal of Materials Science. Materials in Medicine, 25(2), 461-470. http://dx.doi.org/10.1007/s10856-013-5089-9. PMid:24202915.

26. Balabanian, C. A. C. A., Coutinho-Netto, J., Lamano-Carvalho, T. L., Lacerda, S. A., \& Brentegani, L. G. (2006). Biocompatibility of natural latex implanted into dental alveolys of rats. Journal of Oral Science, 48(4), 201-205. http://dx.doi.org/10.2334/ josnusd.48.201. PMid:17220617.

27. Paula, J. S., Ribeiro, V. R. C., Sampaio, R. B., Mendonca, R. J., Haddad, A., Tedesco, A. C., Coutinho-Netto, J., Haendchen, H. A., \& Jorge, R. (2011). Rabbit Rubeosis Iridis Induced by Intravitreal Latex-derived Angiogenic Fraction. Current Eye Research, 36(9), 857-859. http://dx.doi.org/10.3109/027136 83.2011.576797. PMid:21599469.

28. Ferreira, M., Mendonça, R. J., Coutinho-Netto, J., \& Mulato, M. (2009). Angiogenic properties of natural rubber latex biomembranes and the serum fraction of Hevea brasiliensis. Brazilian Journal of Physics, 39(3), 564-569. http://dx.doi. org/10.1590/S0103-97332009000500010.

29. Herculano, R. D., Silva, C. P., Ereno, C., Guimarães, S. A. C., Kinoshita, A., \& Graeff, C. F. O. (2009). Natural rubber latex used as drug delivery system in guided bone regeneration (GBR). Materials Research, 12(2), 253-256. http://dx.doi. org/10.1590/S1516-14392009000200023.

30. Guidelli, É. J., Kinoshita, A., Ramos, A. P., \& Baffa, O. (2013). Silver nanoparticles delivery system based on natural rubber latex membranes. Journal of Nanoparticle Research, 15(4), 1536. http://dx.doi.org/10.1007/s11051-013-1536-2.

31. Herculano, R. D., Tzu, L. C., Silva, C. P., Brunello, C. A., Queiroz, Á. A. A., Kinoshita, A., \& Graeff, C. F. O. (2011). Nitric oxide release using natural rubber latex as matrix. Materials Research, 14(3), 355-359. http://dx.doi.org/10.1590/ S1516-14392011005000055.

32. Hollinger, J. O., \& Kleinschmidt, J. C. (1990). The critical size defect as an experimental model to test bone repair materials. The Journal of Craniofacial Surgery, 1(1), 60-68. http://dx.doi. org/10.1097/00001665-199001000-00011. PMid:1965154.

33. Garber, J. C. (2011). Guide for the care and use of laboratory animals. Washington: National Academies Press. Retrieved in 2017, May 2, from https:/grants.nih.gov/grants/olaw/guidefor-the-care-and-use-of-laboratory-animals.pdf

34. Neves-Junior, W. F. P., Ferreira, M., Alves, M. C. O., Graeff, C. F. O., Mulato, M., Coutinho-Netto, J., \& Bernardes, M. S. (2006). Influence of fabrication process on the final properties of natural-rubber latex tubes for vascular prosthesis. Brazilian Journal of Physics, 36(2B), 586-591. http://dx.doi.org/10.1590/ S0103-97332006000400021.

Received: May 02, 2017 Revised: Sept. 25, 2017 Accepted: Oct. 22, 2017 